Annals of Pure and Applied Mathematics

Vol. 14, No. 3, 2017, 489-496

ISSN: 2279-087X (P), 2279-0888(online)

Published on 9 November 2017

www.researchmathsci.org

DOI: http://dx.doi.org/10.22457/apam.v14n3a16

Annals of

Pure and Applied

Mathematics

\title{
Further Results on Prime Cordial Labeling
}

\author{
A.Sugumaran ${ }^{1}$ and V. Mohan ${ }^{2}$ \\ ${ }^{1,2}$ Department of Mathematics \\ Government Arts College \\ Thiruvannamalai-606603, Tamil Nadu, India. \\ 1e-mail : sugumaran3@yahoo.com \\ ${ }^{2}$ Corresponding author. e-mail : vmb5685@gmail.com
}

Received 1 October 2017; accepted 31October 2017

Abstract. A prime cordial labeling of a graph $\mathrm{G}$ with vertex set $\mathrm{V}(\mathrm{G})$ is a bijection $\mathrm{f}$ : $\mathrm{V}(\mathrm{G}) \rightarrow\{1,2,3, \ldots,|\mathrm{V}(\mathrm{G})|\}$ such that for every edge uv is assigned the label 1 if gcd $(\mathrm{f}(\mathrm{u}), \mathrm{f}(\mathrm{v}))=1$ and 0 if $\operatorname{gcd}(\mathrm{f}(\mathrm{u}), \mathrm{f}(\mathrm{v}))>1$, then the number of edges labeled with 0 and the number of edges labeled with 1 differ by at most 1 . A graph which admits prime cordial labeling is called prime cordial graph. In this paper, we prove that the butterfly graph, W-graph, H-graph and duplication of edges of an H-graph are prime cordial graphs.

Keywords: Labeling of graphs, prime cordial labeling

AMS Mathematics Subject Classification (2010): 05 C78

\section{Introduction}

In this paper, we consider only finite simple undirected graph. Throughout the paper, we denote $\mathrm{V}(\mathrm{G})$ and $\mathrm{E}(\mathrm{G})$ are the vertex set and edge set of the graph $\mathrm{G}$ respectively. A graph labeling is an assignment of integers to vertices or edges or both based on certain criteria. In graph theory various labeling have been studied in recent years, and interestingly they have applications in various fields such as communication network, coding theory, database management, data mining, circuit design, cryptography, etc. For a detailed survey on various graph labeling one can refer Gallian [4].

A binary vertex labeling is labeling of vertices with either 0 or 1 . The concept of cordial labeling was introduced by Cahit [1]. In cordial labeling, each edge $\mathrm{e}=\mathrm{uv}$ in $E(G)$ is assigned by $|f(u)-f(v)|$. Thus binary labeling is called a cordial labeling, if the number of vertices (edges) labeled with 0 and number of vertices (edges) labeled with 1 differ by at most 1 . The concept of cordial labeling is further extended to various labeling such as divisor cordial labeling, product cordial labeling, total product cordial labeling, prime cordial labeling etc.

Vaidya and Shah [7] proved that the graph helm, flower and gear are divisor cordial graphs. Further, they proved that bistar, shadow graph and square graph admit divisor cordial labeling in [9]. Sugumaran and Rajesh [5] proved that swastik graph, jelly fish graph and Petersen graph admit sum divisor cordial labeling. Deshmukh and Shaik [3] proved that the tadpole and olive tree graphs are mean cordial graphs. 


\section{A.Sugumaran and V.Mohan}

In this paper we focus our attention on prime cordial labeling of graphs. Baskar Babuji and Shobana [2] proved that the barycentric subdivision of cycle $C_{n}$ is prime and full binary tree is prime cordial labeling. Vaidya and Shah [8] proved that the square graph of $B_{n, n}$, wheel graph are prime cordial graphs. Sugumaran and Suresh [6] proved that duplication of pair of vertices in path, jelly fish, bistar and actina graph admits prime cordial labeling.

\section{Basic definitions}

In this section, we provide a brief summary of the definitions and notations which are useful for the present work.

Definition 2.1. A prime cordial labeling of a graph $G$ with vertex set $V(G)$ is a bijection $f$ $: \mathrm{V}(\mathrm{G}) \rightarrow\{1,2,3, \ldots,|\mathrm{V}(\mathrm{G})|\}$ such that for every edge $\mathrm{uv}$ is assigned the label 1 if ged $(\mathrm{f}(\mathrm{u}), \mathrm{f}(\mathrm{v}))=1$ and 0 if $\operatorname{gcd}(\mathrm{f}(\mathrm{u}), \mathrm{f}(\mathrm{v}))>1$, then the number of edges labeled with 0 and the number of edges labeled with 1 differ by at most 1 . A graph which admits prime cordial labeling is called prime cordial graph.

Definition 2.2. A cycle butterfly graph $B_{n, a m}$ consists of two cycles of same order $\mathrm{n}$ sharing a common vertex together with an arbitrary number of $\mathrm{m}$ pendant vertices attached at the common vertex.

Definition 2.3. Consider the two copies of the star graph $\mathrm{K}_{1, \mathrm{n}}$. If the last pendant vertex in the first copy of $K_{1, n}$ is merged with the initial pendant vertex in the second copy of $K_{1}$, $n$ then the resulting graph is called the $W$-graph and it is denoted by $\mathrm{W}_{2 \mathrm{n}+1}$. Note that $\left|\mathrm{E}\left(\mathrm{W}_{2 \mathrm{n}+1}\right)\right|=2 \mathrm{n}$ and $\left|\mathrm{V}\left(\mathrm{W}_{2 \mathrm{n}+1}\right)\right|=2 \mathrm{n}+1$.

Definition 2.4. Let $P_{n}^{1}, P_{n}^{2}$ be any two paths with $\mathrm{n}$ vertices. Let $\mathrm{V}\left(P_{n}^{1}\right)=\left\{\mathrm{u}_{1}, \mathrm{u}_{2}, \mathrm{u}_{3}, \ldots\right.$, $\left.\mathrm{u}_{\mathrm{n}}\right\}$ and $\mathrm{V}\left(P_{n}^{2}\right)=\left\{\mathrm{v}_{1}, \mathrm{v}_{2}, \mathrm{v}_{3}, \ldots, \mathrm{v}_{\mathrm{n}}\right\}$. We join the vertices $\frac{u_{\frac{n+1}{2}}}{2}$ and $\frac{v_{n+1}}{2}$ by an edge, if $\mathrm{n}$ is odd. Otherwise join the vertices $u_{\frac{n}{2}}$ and $v_{\frac{n}{2}+1}$, then the resulting graph is called a $H$ graph on $2 \mathrm{n}$ vertices.

Definition 2.5. The duplication of an edge $\mathrm{e}=\mathrm{uv}$ of a graph $\mathrm{G}$ is the graph $\mathrm{G}^{\prime}$ obtained from $\mathrm{G}$ by adding a new vertex $\mathrm{v}^{\prime}$ to $\mathrm{G}$ such that $\mathrm{v}^{\prime}$ is adjacent to both $\mathrm{u}$ and $\mathrm{v}$.

\section{Main results}

Lemma 3.1. Cycle butterfly graph $B_{n, m}$ admits prime cordial labeling, where $n=3$ and for all integer values of $m>2$ and $m=1$.

Proof: Let $\mathrm{G}$ be a cycle butterfly graph with two cycle of same order $n$. Let $u$ be the common vertex and let $u_{2}, u_{3}, \ldots, u_{n}$ be the vertices of left wing and $v_{2}, v_{3}, \ldots, v_{n}$ be the vertices of right wing and let $\mathrm{x}_{1}, \mathrm{x}_{2}, \ldots, \mathrm{x}_{\mathrm{m}}$ be the pendant vertices of G. Clearly $|\mathrm{V}(\mathrm{G})|=$ $2 n+m-1$ and $|E(G)|=2 n+m$. We define a vertex labeling $f: V(G) \rightarrow\{1,2,3, \ldots, 2 n+m-$ $1\}$ as follows.

Let us consider the following three cases.

Case 1. When $\mathrm{n}=3$ and $\mathrm{m}=1$.

$\mathrm{f}(\mathrm{u})=2, \mathrm{f}\left(\mathrm{u}_{2}\right)=4, \mathrm{f}\left(\mathrm{u}_{3}\right)=6, \mathrm{f}\left(\mathrm{v}_{2}\right)=1, \mathrm{f}\left(\mathrm{v}_{3}\right)=3$ and $\mathrm{f}\left(\mathrm{x}_{1}\right)=5$. 
Further Results on Prime Cordial Labeling

Case 2. When $\mathrm{n}=3$ and $\mathrm{m}=3$.

$\mathrm{f}(\mathrm{u})=2, \mathrm{f}\left(\mathrm{u}_{2}\right)=4, \mathrm{f}\left(\mathrm{u}_{3}\right)=6, \mathrm{f}\left(\mathrm{v}_{2}\right)=1, \mathrm{f}\left(\mathrm{v}_{3}\right)=3$, and $\mathrm{f}\left(\mathrm{x}_{1}\right)=5, \mathrm{f}\left(\mathrm{x}_{2}\right)=7, \mathrm{f}\left(\mathrm{x}_{3}\right)=8$.

Case 3. When $\mathrm{n}=3$ and $\mathrm{m} \geq 4$.

$\mathrm{f}(\mathrm{u})=2, \mathrm{f}\left(\mathrm{u}_{2}\right)=4, \mathrm{f}\left(\mathrm{u}_{3}\right)=6, \mathrm{f}\left(\mathrm{v}_{2}\right)=3, \mathrm{f}\left(\mathrm{v}_{3}\right)=9$ and we label the remaining pendant vertices uniquely from the set $\{1,5,7,8\} \cup\{10,11,12, \ldots, 2 n+m-1\}$ in ascending order.

In view of the above labeling pattern we have $\left|e_{f}(0)-e_{f}(1)\right| \leq 1$.

Hence $\mathrm{G}$ is a prime cordial graph.

Theorem 3.2. Cycle butterfly graph $B_{n, m}$ admits prime cordial labeling, where $n \geq 4$ and $m \geq 1$.

Proof: Let $\mathrm{G}$ be a cycle butterfly graph with two cycle of same order $\mathrm{n}$. Let $\mathrm{u}$ be the common vertex and let $u_{2}, u_{3}, \ldots, u_{n}$ be the vertices of left wing and $v_{2}, v_{3}, \ldots, v_{n}$ be the vertices of right wing and let $\mathrm{x}_{1}, \mathrm{x}_{2}, \ldots, \mathrm{x}_{\mathrm{m}}$ be the pendant vertices of $\mathrm{G}$. Clearly $|\mathrm{V}(\mathrm{G})|=$ $2 \mathrm{n}+\mathrm{m}-1$ and $|\mathrm{E}(\mathrm{G})|=2 \mathrm{n}+\mathrm{m}$. We define a vertex labeling $\mathrm{f}: \mathrm{V}(\mathrm{G}) \rightarrow\{1,2,3, \ldots, 2 \mathrm{n}+\mathrm{m}-$ $1\}$ as follows.

Let us consider the following five cases.

Case 1. When $\mathrm{n}=4$ and $\mathrm{m}=1$.

$\mathrm{f}(\mathrm{u})=2$,

$\mathrm{f}\left(\mathrm{u}_{\mathrm{i}}\right)=2 \mathrm{i} ; 2 \leq i \leq 4$,

$\mathrm{f}\left(\mathrm{v}_{2}\right)=1, \mathrm{f}\left(\mathrm{v}_{3}\right)=3, \mathrm{f}\left(\mathrm{v}_{4}\right)=5, \mathrm{f}\left(\mathrm{x}_{1}\right)=7$.

Case 2. When $\mathrm{n}=4$ and $\mathrm{m} \geq 2$.

$\mathrm{f}(\mathrm{u})=2$,

$\mathrm{f}\left(\mathrm{u}_{\mathrm{i}}\right)=2 \mathrm{i} ; 2 \leq i \leq 4$,

$\mathrm{f}\left(\mathrm{v}_{2}\right)=1, \mathrm{f}\left(\mathrm{v}_{3}\right)=3, \mathrm{f}\left(\mathrm{v}_{4}\right)=9$. We label the remaining pendant vertices from the set

$\{5,7\} \cup\{10,11,12, \ldots, 2 n+m-1\}$ in ascending order.

Case 3. When $\mathrm{n}=5$ and $\mathrm{m} \geq 1$.

$\mathrm{f}(\mathrm{u})=2$,

$\mathrm{f}\left(\mathrm{u}_{\mathrm{i}}\right)=2 \mathrm{i} ; 2 \leq i \leq 5$,

$\mathrm{f}\left(\mathrm{v}_{2}\right)=1, \mathrm{f}\left(\mathrm{v}_{3}\right)=3, \mathrm{f}\left(\mathrm{v}_{4}\right)=9, \mathrm{f}\left(\mathrm{v}_{5}\right)=5$. We label the remaining pendant vertices uniquely from the set $\{7\} \cup\{11,12,13, \ldots, 2 n+m-1\}$ in ascending order.

Case 4. When $n=6$ and $m \geq 1$.

$\mathrm{f}(\mathrm{u})=2$,

$\mathrm{f}\left(\mathrm{u}_{\mathrm{i}}\right)=2 \mathrm{i} ; 2 \leq i \leq 6$,

$\mathrm{f}\left(\mathrm{v}_{2}\right)=1, \mathrm{f}\left(\mathrm{v}_{3}\right)=3, \mathrm{f}\left(\mathrm{v}_{4}\right)=9, \mathrm{f}\left(\mathrm{v}_{5}\right)=5, \mathrm{f}\left(\mathrm{v}_{6}\right)=7$. We label the remaining pendant vertices uniquely from the set $\{11\} \cup\{13,14,15, \ldots, 2 n+m-1\}$ in ascending order.

Case 5. When $n \geq 7$ and $m \geq 1$.

$\mathrm{f}(\mathrm{u})=2$,

$\mathrm{f}\left(\mathrm{u}_{\mathrm{i}+1}\right)=2 \mathrm{i}+2 ; 1 \leq i \leq \mathrm{n}-1$,

$\mathrm{f}\left(\mathrm{v}_{2}\right)=1, \mathrm{f}\left(\mathrm{v}_{3}\right)=3, \mathrm{f}\left(\mathrm{v}_{4}\right)=9, \mathrm{f}\left(\mathrm{v}_{5}\right)=5, \mathrm{f}\left(\mathrm{v}_{6}\right)=7$, 


\section{A.Sugumaran and V.Mohan}

$\mathrm{f}\left(\mathrm{v}_{\mathrm{i}+6}\right)=2 \mathrm{i}+9 ; 1 \leq i \leq \mathrm{n}-6$, where $\mathrm{n}>6$. We label the remaining pendant vertices uniquely from the set $\{2 n-1\} \cup\{2 n+1,2 n+2,2 n+3, \ldots, 2 n+m-1\}$ in ascending order.

In view of all the above cases, we have $\left|e_{f}(0)-e_{f}(1)\right| \leq 1$. Hence $G$ is a prime cordial graph.

Example 1. Prime cordial labeling of cycle butterfly graph $B_{5,4}$ is shown in Figure 1.

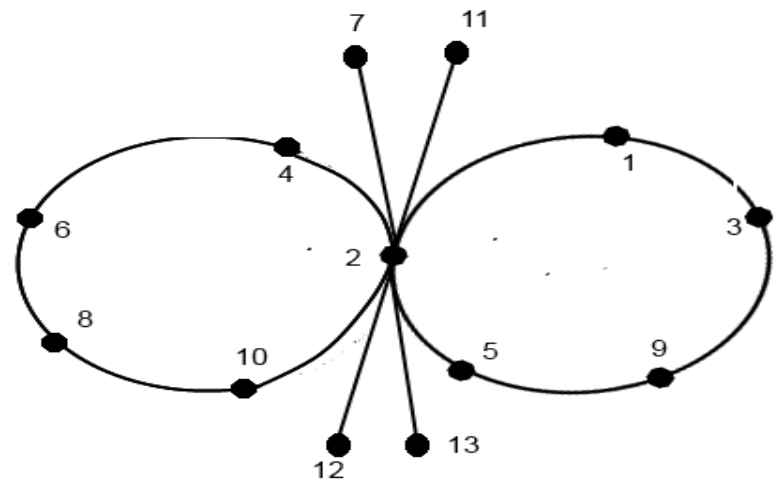

Figure 1: Prime cordial labeling of cycle butterfly graph $\mathrm{B}_{5,4}$.

Theorem 3.3. The $\mathrm{W}$-graph $\mathrm{W}_{2 \mathrm{n}+1}$ is a prime cordial graph.

Proof: Let $\mathrm{K}_{1, \mathrm{n}}^{1}$ and $\mathrm{K}_{1, \mathrm{n}}^{2}$ be the first and second copies of star graph with apex vertex a and $\mathrm{b}$. Let $\mathrm{V}\left(\mathrm{K}_{1, \mathrm{n}}^{1}\right)=\left\{\mathrm{a}, \mathrm{x}_{1}, \mathrm{x}_{2}, \mathrm{x}_{3}, \ldots, \mathrm{x}_{\mathrm{n}}\right\}$ and $\mathrm{V}\left(\mathrm{K}_{1, \mathrm{n}}^{2}\right)=\left\{\mathrm{b}, \mathrm{y}_{1}, \mathrm{y}_{2}, \mathrm{y}_{3}, \ldots, \mathrm{y}_{\mathrm{n}}\right\}$. We obtain the $\mathrm{W}$-graph by adjoining $\mathrm{x}_{\mathrm{n}}$ and $\mathrm{y}_{1}$. Let $\mathrm{G}$ be the W-graph. Then $|\mathrm{V}(\mathrm{G})|=2 \mathrm{n}+1$ and $|\mathrm{E}(\mathrm{G})|=$ $2 \mathrm{n}$.

The vertex labeling of $\mathrm{f}: \mathrm{V}(\mathrm{G}) \rightarrow\{1,2,3, \ldots, 2 \mathrm{n}+1\}$ is defined as follows.

$\mathrm{f}\left(\mathrm{x}_{\mathrm{n}}=\mathrm{y}_{1}\right)=1$,

$\mathrm{f}\left(\mathrm{x}_{\mathrm{i}}\right)=2 \mathrm{i}+2 ; 1 \leq i \leq \mathrm{n}-1$.

From the set $\{3,5,7, \ldots, 2 \mathrm{n}+1\}$, choose a number $\mathrm{p}$ such that it divides only one of the number from this set other than $p$. In this case we assign vertex $b$ as $p$ and the remaining numbers from the above set are assigned to the vertices $\mathrm{y}_{2}, \mathrm{y}_{3}, \ldots, \mathrm{y}_{\mathrm{n}}$ uniquely in any order. Clearly $\mathrm{f}$ is a prime cordial labeling.

Hence the $\mathrm{W}$-graph $\mathrm{W}_{2 \mathrm{n}+1}$ is prime cordial graph.

Example 2. Prime cordial labeling of the graph $\mathrm{W}_{8}$ is shown in Figure 2.
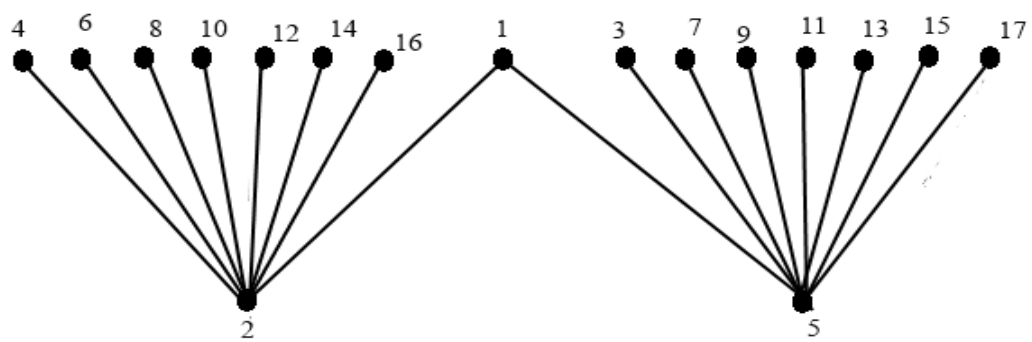

Figure 2: Prime cordial labeling of the graph $\mathrm{W}_{8}$. 
Further Results on Prime Cordial Labeling

Theorem 3.4. H-graph admits prime cordial labeling.

Proof: Let $\mathrm{G}$ be a H-graph with $2 \mathrm{n}$ vertices and $2 \mathrm{n}-1$ edges. Let $P_{n}^{1}$ and $P_{n}^{2}$ be the parallel paths in $\mathrm{G}$ with $\mathrm{n}$ vertices and let $\mathrm{V}\left(P_{n}^{1}\right)=\left\{\mathrm{u}_{\mathrm{i}}: 1 \leq i \leq \mathrm{n}\right\}$ and $\mathrm{V}\left(P_{n}^{2}\right)=\left\{\mathrm{v}_{\mathrm{i}}: 1\right.$ $\leq i \leq \mathrm{n}\}$. We consider the following two cases for the labeling of $\mathrm{G}$.

Case 1. When $\mathrm{n}$ is even.

Here the vertices $u_{\frac{n}{2}}$ and $v_{\frac{n}{2}+1}$ are connected by an edge.

The vertex labeling of $\mathrm{f}: \mathrm{V}(\mathrm{G}) \rightarrow\{1,2,3, \ldots, 2 \mathrm{n}\}$ is defined as follows.

$\mathrm{f}\left(\mathrm{u}_{\mathrm{i}}\right)=2 \mathrm{i}-1 ; 1 \leq i \leq \mathrm{n}$,

$\mathrm{f}\left(v_{\frac{n}{2}+1}\right)=2$,

$\mathrm{f}\left(\mathrm{v}_{\mathrm{j}}\right)=2 \mathrm{j}+2 ; 1 \leq j \leq \frac{n}{2}$,

$\mathrm{f}\left(\mathrm{v}_{\mathrm{k}}\right)=2 \mathrm{k} ; \frac{n}{2}+1<k \leq n$.

Case 2. When $\mathrm{n}$ is odd.

Here the vertices $u_{\frac{n+1}{2}}$ and $v_{\frac{n+1}{2}}$ are connected by an edge.

The vertex labeling of $\mathrm{f}: \mathrm{V}(\mathrm{G}) \rightarrow\{1,2,3, \ldots, 2 \mathrm{n}\}$ is defined as follows.

$\mathrm{f}\left(\mathrm{u}_{\mathrm{i}}\right)=2 \mathrm{i}-1 ; 1 \leq i \leq \mathrm{n}$,

$\mathrm{f}\left(\frac{v_{n+1}}{2}\right)=2$,

$\mathrm{f}\left(\mathrm{v}_{\mathrm{j}}\right)=2 \mathrm{j}+2 ; 1 \leq j \leq \frac{n-1}{2}$,

$\mathrm{f}\left(\mathrm{v}_{\mathrm{k}}\right)=2 \mathrm{k} ; \frac{n-1}{2}<k \leq n$.

In view of the above labeling pattern, we have $\left|e_{f}(0)-e_{f}(1)\right|=1$.

Hence the H-graph is a prime cordial graph.

Example 3. Prime cordial labeling of the graph $\mathrm{H}_{5}$ is shown in Figure 3.

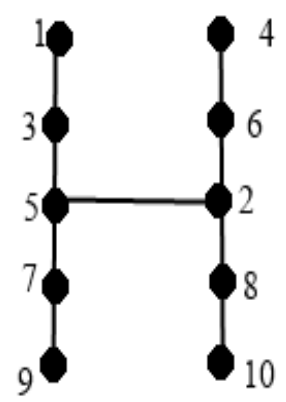

Figure 3: Prime cordial labeling of the graph $\mathrm{H}_{5}$.

Example 4. Prime cordial labeling of the graph $\mathrm{H}_{6}$ is shown in Figure 4. 
A.Sugumaran and V.Mohan

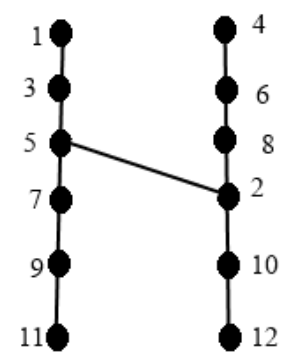

Figure 4: Prime cordial labeling of the graph $\mathrm{H}_{6}$.

Theorem 3.5. Duplicating of all edges of an $\mathrm{H}$-graph $\mathrm{H}_{\mathrm{n}}$ admits prime cordial labeling.

Proof: Consider an H-graph. Let $\mathrm{u}_{1}, \mathrm{u}_{2}, \mathrm{u}_{3}, \ldots, \mathrm{u}_{\mathrm{n}}$ and $\mathrm{v}_{1}, \mathrm{v}_{2}, \mathrm{v}_{3}, \ldots, \mathrm{v}_{\mathrm{n}}$ be the consecutive vertices of first and second vertical paths of the $\mathrm{H}$-graph respectively. Let $\mathrm{G}$ be the graph obtained by duplicating of all the edges $\mathrm{u}_{1} \mathrm{u}_{2}, \mathrm{u}_{2} \mathrm{u}_{3}, \mathrm{u}_{3} \mathrm{u}_{4}, \ldots, \mathrm{u}_{\mathrm{n}-1} \mathrm{u}_{\mathrm{n}}$, and $\mathrm{v}_{1} \mathrm{v}_{2}, \mathrm{v}_{2} \mathrm{v}_{3}, \mathrm{v}_{3} \mathrm{v}_{4}, \ldots$, $\mathrm{v}_{\mathrm{n}-1} \mathrm{v}_{\mathrm{n}}$, by new vertices $\mathrm{u}_{1}^{\prime}, \mathrm{u}_{2}^{\prime}, \mathrm{u}_{3}^{\prime}, \ldots, \mathrm{u}_{\mathrm{n}-1}^{\prime}$ and $\mathrm{v}_{1}^{\prime}, \mathrm{v}_{2}{ }_{2}, \mathrm{v}_{3}{ }_{3}, \ldots, \mathrm{v}_{\mathrm{n}-1}^{\prime}$ respectively. Let $\mathrm{w}$ be a new vertex obtained by duplicating the edge $u_{n+1} v_{n+1}$, when $n$ is odd or duplication of the edge $u_{\frac{n}{2}} v_{\frac{n}{2}+1}$, when $n$ is even. Then $|\mathrm{V}(\mathrm{G})|^{2}=4 \mathrm{n}^{2}-1$ and $|\mathrm{E}(\mathrm{G})|=6 \mathrm{n}-3$. We define $\mathrm{f}$ : $\mathrm{V}(\mathrm{G}) \rightarrow\{1,2,3, \ldots, 4 \mathrm{n}-1\}$ is defined as follows, $\mathrm{f}(\mathrm{w})=1$.

We consider the following two cases for the labeling of remaining vertices in G.

Case 1. When $\mathrm{n}=3$.

$\mathrm{f}\left(\mathrm{u}_{1}\right)=3, \mathrm{f}\left(\mathrm{u}_{2}\right)=5, \mathrm{f}\left(\mathrm{u}_{3}\right)=11, \mathrm{f}\left(\mathrm{v}_{1}\right)=4, \mathrm{f}\left(\mathrm{v}_{2}\right)=2, \mathrm{f}\left(\mathrm{v}_{3}\right)=10, \mathrm{f}\left(\mathrm{u}_{1}^{\prime}\right)=9, \mathrm{f}\left(\mathrm{u}_{2}^{\prime}\right)=7, \mathrm{f}\left(\mathrm{v}_{1}^{\prime}\right)=$ 6 and $\mathrm{f}\left(\mathrm{v}_{2}^{\prime}\right)=8$.

Case 2. When $\mathrm{n}>3$.

$\mathrm{f}\left(\mathrm{u}_{1}\right)=3, \mathrm{f}\left(\mathrm{u}_{2}\right)=5, \mathrm{f}\left(\mathrm{u}_{3}\right)=11, \mathrm{f}\left(\mathrm{u}_{1}^{\prime}\right)=9$,

$\mathrm{f}\left(\mathrm{u}_{\mathrm{i}+3}\right)=11+4 \mathrm{i} ; 1 \leq i \leq \mathrm{n}-3$,

$\mathrm{f}\left(\mathrm{u}_{\mathrm{i}}^{\prime}\right)=\mathrm{f}\left(\mathrm{u}_{\mathrm{i}}\right)+2 ; 2 \leq i \leq \mathrm{n}-1$.

Subcase 2(i). When $\mathrm{n}$ is even.

$\mathrm{f}\left(v_{\frac{n}{2}+1}\right)=2$,

$\mathrm{f}\left(\mathrm{v}_{\mathrm{j}}\right)=2 \mathrm{j}+2 ; 1 \leq j \leq \frac{n}{2}$,

$\mathrm{f}\left(\mathrm{v}_{\mathrm{k}}\right)=2 \mathrm{k} ; \frac{n}{2}+1<k \leq n$,

$\mathrm{f}\left(\mathrm{v}_{\mathrm{j}}^{\prime}\right)=2 \mathrm{n}+2 \mathrm{j} ; 1 \leq j \leq \mathrm{n}-1$.

Subcase 2(ii). When $\mathrm{n}$ is odd.

$\mathrm{f}\left(v_{\frac{n+1}{2}}\right)=2$,

$\mathrm{f}\left(\mathrm{v}_{\mathrm{j}}\right)=2 \mathrm{j}+2 ; 1 \leq j \leq \frac{n-1}{2}$,

$\mathrm{f}\left(\mathrm{v}_{\mathrm{k}}\right)=2 \mathrm{k} ; \frac{n-1}{2}<k \leq n$,

$\mathrm{f}\left(\mathrm{v}_{\mathrm{j}}^{\prime}\right)=2 \mathrm{n}+2 \mathrm{j} ; 1 \leq j \leq \mathrm{n}-1$.

In view of the above labeling pattern, we have $\left|e_{f}(0)-e_{f}(1)\right|=1$, and hence $f$ is a prime cordial labeling. 
Further Results on Prime Cordial Labeling

Example 5. Prime cordial labeling of duplication of all edges of $\mathrm{H}_{3}$-graph is shown in Figure 5.

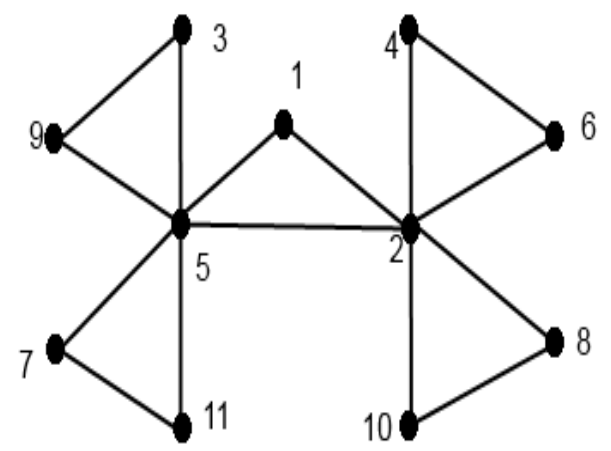

Figure 5: Prime cordial labeling of duplication of all edges of $\mathrm{H}_{3}$-graph.

Example 6. Prime cordial labeling of duplication of all edges of $\mathrm{H}_{6}$-graph is shown in Figure 6.

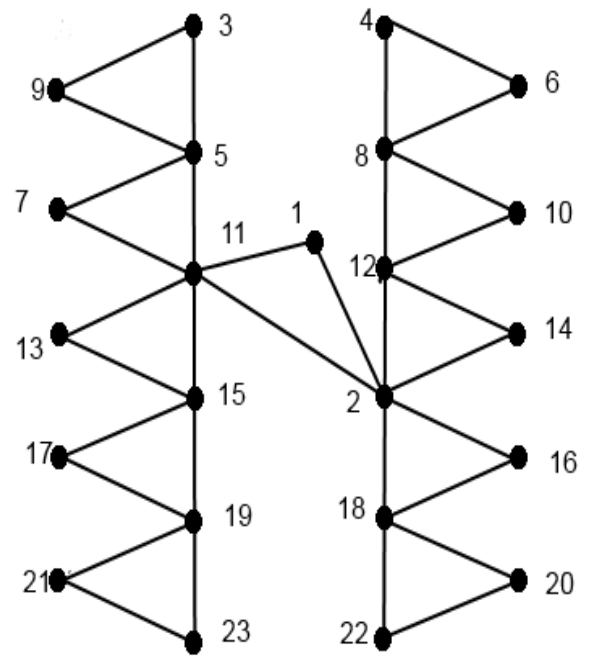

Figure 6: Prime cordial labeling of duplication of all edges of $\mathrm{H}_{6}$-graph.

\section{Concluding remarks}

Prime cordial labeling is explored for several graphs. In this paper we proved that the butterfly graph $B_{n, m}, W$-graph, H-graph and duplication of all edges of an $\mathrm{H}$-graph are prime cordial graphs. It is an interesting open area of research for applying prime cordial labeling for the remaining unproven graphs.

Acknowledgement. We are indebted to anonymous referee for his valuable suggestions and improvement of this paper. 


\section{A.Sugumaran and V.Mohan}

\section{REFERENCES}

1. I.Cahit, Cordial graphs: A weaker version of graceful and harmonious graphs, Ars Combinatoria, 23 (1987) 201 - 207.

2. B.Babuji and L.Shobana, Prime and prime cordial labeling, International Journal of

3. Contemp. Math. Sciences, 5 (47) (2010) 2347- 2356.

4. U.Deshmukh and V.Y.Shaikh, Mean cordial labeling of tadpole and olive tree, Annals of Pure and Applied Mathematics, 11 (2) (2016) 109 - 116.

5. J.A.Gallian, A Dynamic Survey of Graph Labeling, (2016). ?????

6. A.Sugumaran and K.Rajesh, Some new results on sum divisor cordial graphs, Annals of Pure and Applied Mathematics, 14 (1) (2017) 45 - 52.

7. A.Sugumaran and K.Suresh, A special class of prime cordial graphs, International Journal of Pure and Applied Mathematics, 114 (6) (2017) 41 - 48.

8. S.K.Vaidya and N.H.Shah, Further results on divisor cordial labeling, Annals of Pure and Applied Mathematics, 4 (2) (2013) 150 - 159.

9. S.K.Vaidya and N.H.Shah, Prime cordial labeling of some graphs, Open Journal of Discrete Mathematics, 2 (2012) 11 - 16.

10. S.K.Vaidya and N.H.Shah, Some star and bistar related divisor cordial graphs, Annals of Pure and Applied Mathematics, 3 (1) (2013) 67 - 77. 